\title{
Olhares Antagônicos para a Educação Superior Brasileira
}

\author{
Antagonic Lights for Brazilian Higher Education
}

\author{
Maisa Oliveira Melo Ferraz; ; Ennia Débora Passos Braga Pires*a; Soraia Kfouri Salerno ${ }^{\mathrm{b}}$ \\ aUniversidade Estadual do Sudoeste da Bahia, Programa de Pós-Graduação Stricto Sensu em Educação. BA, Brasil. \\ bUniversidade Estadual de Londrina, Departamento de Educação. PR, Brasil. \\ *E-Mail: enniadebora@uesb.edu.br \\ Recebido em: 30/04/19; Aceito em: 09/08/19
}

\begin{abstract}
Resumo
O presente artigo objetiva apresentar as divergentes percepções existentes para a Educação Superior ao se analisar o processo de redemocratização realizado no país até os dias atuais. Para isso, discutem-se os desafios e os impasses das políticas educacionais brasileiras quanto à gestão e ao financiamento, desigualdades de acesso e permanência. Neste sentido, foi realizada uma pesquisa teórica e documental, que analisou documentos legais, tais como: a Constituição Federal, Lei das Diretrizes e Bases da Educação Nacional e o Plano Nacional de Educação (PNE 2014-2024), em específico, uma análise da Meta 12 do PNE, que trata do Ensino Superior, bem como dos dados levantados por órgãos públicos para quantificação dos investimentos que o Brasil tem realizado em Educação. Ao trazer reflexões sobre as atuais políticas educacionais e revelar sobre quais olhares essas estão sendo desenhadas, denuncia que o caminho adotado vai em direção antagônica às necessidades da sociedade, ou melhor, em um sentido divergente de uma educação emancipadora, que versa para uma sociedade para além do capital. Conclui defendendo que o rompimento dessa lógica só será possível com a adoção de uma perspectiva educacional diferente, uma educação que transforme o trabalhador em um agente político que pensa, age e usa a palavra como arma para transformar o mundo.
\end{abstract}

Palavras-chave: Capital. Educação Emancipadora. Políticas Educacionais.

\begin{abstract}
This article aims to present the divergent perceptions that exist for Higher Education when analyzing the redemocratization process carried out in the country up to the present day. For this, it discusses the challenges and impasses of Brazilian educational policies regarding management and financing, inequalities of access and permanence. In this sense, a theoretical and documentary research was carried out, which analyzed legal documents, such as the Federal Constitution, the Law of Directives and Bases of National Education and the National Education Plan (PNE 2014-2024), in specific analysis, an analysis of the PNE Target 12 that deals with Higher Education, as well as data collected by public agencies to quantify the investments that Brazil has made in Education. By bringing reflections on current educational policies and revealing what looks are being drawn, it denounces that the path adopted goes in antagonistic direction to the needs of the society, or rather, in a divergent sense of an emancipatory education that is for a society beyond of capital. It concludes by arguing that breaking this logic will only be possible by adopting a different educational perspective, an education that turns the worker into a political agent who thinks, acts and uses the word as a weapon to transform the world.
\end{abstract}

Keywords: Capital. Emancipating Education. Educational Policies.

\section{Introdução}

A história da gênese do Estado Brasileiro é atravessada por séculos de um período colonial (1500-1822), em que foi totalmente dependente da metrópole, e teve a escravidão como um grande comércio. Mesmo após a independência do Brasil, no período imperial (1822-1889), apesar de um Estado autônomo, o país permaneceu escravocrata. Nesse sentido, tanto na relação do Estado com a sociedade quanto com a elite social, como base da pirâmide, forjou-se a ideia da existência de um segmento social que não era digno de participar da vida legal e oficial do país. A pobreza tinha, então, raça, etnia, gênero e localização.

As ideologias políticas que estavam em discussão em diferentes países pouco afetavam a realidade social e educacional brasileira. As políticas educacionais do Brasil sempre se mostraram inconsistentes. Na verdade, a história da Educação Brasileira não registra, ao longo do período colonial, nem do Império, preocupação com políticas públicas de Educação.

A partir de 1889 até os dias atuais se encontra na República, período este marcado pela abolição da escravidão e inserção do trabalho livre. De acordo com Domingues (2008), o pósabolição da escravatura, em 1888, seguido da Proclamação da República, em 1889, configuraram um período marcante para o futuro das camadas populacionais historicamente excluídas, como, por exemplo, os negros brasileiros. Entre as suas reivindicações, a educação se tornou prioritária, pois o analfabetismo e a lenta inserção nas escolas oficiais se constituíam em um dos principais problemas dessa população para a inserção no mundo do trabalho.

O Estado Brasileiro se mostrou omisso e ausente das políticas sociais, em especial, para os recém-libertos. Pior, o 
Estado intensificou o apartheid racial existente na sociedade.

Diante do histórico de um Estado escravocrata, patrimonialista e clientelista, a educação teve sua gênese para atender aos interesses da classe dominante e para a manutenção do status quo.

Além do próprio apartheid racial existente na sociedade brasileira, ainda se convive com o apartheid social, como bem frisado por Mészáros (2008), pois quando se observa a situação educacional do país, fica claro que o simples acesso à escola é condição necessária, mas não suficiente para tirar das sombras do esquecimento social milhões de pessoas, cuja existência só é reconhecida nos quadros estatísticos. O deslocamento do processo de exclusão educacional não ocorre, principalmente, na questão do acesso à escola, mas sim dentro dessa por meio das instituições da educação formal. Mészáros (2008) salienta que não é apenas a modificação política dos processos educacionais - que praticam e agravam o apartheid social, mas a reprodução da estrutura de valores, que contribui para perpetuar uma concepção de mundo baseada na sociedade mercantil.

Logo, quando se volta às atuais políticas e às diretrizes educacionais dos últimos anos percebe-se com raras exceções, que não tem sido possível romper a tensão entre as intenções declaradas e as medidas efetivas. Se, por um lado, as políticas educacionais expressam intenções de ampliar a autonomia e a participação das escolas e dos professores, por outro, a lógica liberal aplicada ao sistema de ensino acaba impedindo a efetivação de tais medidas que requerem investimentos.

Neste contexto, o que o país tem vivenciado, nos últimos anos, intensificado a partir do "golpe" parlamentar de 2016, são cortes públicos para a Educação, especificamente, para a Educação Superior. O Estado brasileiro, através de seus gestores, tem se distanciado da lógica de um país crítico, com formação de uma sociedade liberta das amarras do capital. $\mathrm{Na}$ verdade, o que se tem posto à sociedade e, em especial, à população historicamente excluída, é um Estado máximo para os interesses do capital e mínimo às questões sociais.

\section{Desenvolvimento}

\subsection{Metodologia}

Diante de tais questões, ao analisar o Plano Nacional de Educação - PNE, Plano de Desenvolvimento Educacional PDE, os dispositivos existentes da Lei de Diretrizes e Bases LDB para a educação se observam os antagonismos existentes das gestões públicas dos representantes postos para governar o país. Daí como bem frisado pelo filósofo Rousseau ao tratar sobre a política dos ingleses, o povo se enganava em pensar ser livre, pois só eram no período das eleições, após isso, permaneciam escravos, como pode ser constatado a seguir:

Os deputados do povo não são, nem podem ser seus representantes; não passam de comissários seus, nada podendo concluir definitivamente. É nula toda lei que o povo diretamente não ratificar, em absoluto, não é lei. $\mathrm{O}$ povo inglês pensa ser livre e muito se engana, pois só o é durante as eleições dos membros do parlamento: uma vez estes eleitos, ele é escravo, não é nada (ROUSSEAU, 1983, p.108).

Para isto, faz-se necessário compreender a relação da educação e o atual modelo econômico e político hegemônico, ou seja, um modelo que prevê apenas uma educação "básica" e não libertadora a fim de promover a luta por uma transformação radical de tal modelo, como destaca Mészáros (2008), para o qual a educação teria como função transformar o trabalhador em um agente político, que pensa, que age e que usa a palavra como arma para transformar o mundo.

Foram discutidos desafios e impasses das políticas educacionais brasileiras quanto à gestão e ao financiamento, desigualdades de acesso e permanência. Neste sentido, foi realizada uma pesquisa teórica e documental, que analisou documentos legais, tais como: a Constituição Federal - CF, LDB e o PNE 2014-2024, em específico, uma análise da Meta 12 do PNE que trata do Ensino Superior, bem como dos dados levantados por órgãos públicos para quantificação dos investimentos que o Brasil tem realizado em Educação.

Ao trazer reflexões sobre as atuais políticas educacionais e revelar sobre quais olhares essas estão sendo desenhadas, denuncia-se que o caminho adotado vai em direção antagônica às necessidades da sociedade, ou melhor, em um sentido divergente de uma educação emancipadora, que versa para uma sociedade para além do capital.

\subsection{Discussão}

\subsubsection{Conjunturas da Educação brasileira: análise do PNE, LDB e outros documentos legais}

As discussões em torno dos conceitos de Estado, nação, povo, direitos e deveres têm sofrido modificações ao longo da história. Por consequência disso, as políticas públicas são influenciadas pelo contexto social, econômico e político de cada época da história. Ainda vale ressaltar também quanto às influências das crises políticas nacionais e internacionais, que provocam transformações nas relações de poder dentro e fora de cada país.

Nesse sentido, os múltiplos aspectos que se vive no mundo exige que seja desenvolvida, em cada cidadão, não apenas a consciência crítica voltada para o jogo político que viabiliza uma emancipação social, mas também uma emancipação humana - que possa conduzir a uma sociedade democrática. Mészáros (2008) ensina que pensar a sociedade que tem parâmetro o ser humano exige superação da lógica desumanizadora do capital, que tem no individualismo, no lucro e na competição seus fundamentos. Mészáros (2008) ao citar Gramsci (2004), coloca fim à separação entre Homo Saber e Homo Sapiens, ele destaca que educar é resgatar o sentido estruturante da educação e de sua relação com o trabalho, as suas possibilidades criativas e emancipatórias. Lombardi (2010), com relação ao trabalho, complementa que a educação nas obras de Marx e Engels se dissolve nas situações em que ele aparece no modo capitalista de produção. 
Neste sentido, o autor destaca que a partir do momento que ocorre uma nova divisão do trabalho entre os que sabem e os que fazem, aparece a concretude do próprio desenvolvimento do trabalho como condição necessária na divisão social do trabalho.

No caso da Educação brasileira, a tomada de consciência do problema por parte da sociedade, em particular, inicia-se na constatação do dia a dia das escolas e com a convivência com a população escolarizável. Os dados estatísticos apenas comprovam matematicamente as dimensões da situação real.

Ao analisar alguns dispositivos legais, observa-se que no discurso documental, expresso no marco legal, há preocupação em assegurar o desenvolvimento do ensino nos seus diversos níveis, até mesmo para se buscar uma melhora da realidade educacional brasileira, quando se considera, por exemplo, as metas do Plano Nacional de Educação, porém na prática, não se vislumbra atitudes do governo para alcançar efetivamente tais metas.

A Constituição da República Federativa do Brasil, no artigo 214 (BRASIL, 2016, p. 125), estabelece o Plano Nacional de Educação e destaca seu papel no direcionamento de esforços e investimentos para a melhoria da educação ao instituir diretrizes, metas e estratégias que devem reger e orientar as iniciativas e políticas públicas educacionais:

A lei estabelecerá o plano nacional de educação, de duração decenal, com o objetivo de articular o sistema nacional de educação em regime de colaboração e definir diretrizes, objetivos, metas e estratégias de implementação para assegurar a manutenção e desenvolvimento do ensino em seus diversos níveis, etapas e modalidades por meio de ações integradas dos poderes públicos das diferentes esferas federativas que conduzam a: (EC no 59/2009) I - erradicação do analfabetismo; II - universalização do atendimento escolar; III - melhoria da qualidade do ensino; IV - formação para o trabalho; V - promoção humanística, científica e tecnológica do País; VI - estabelecimento de meta de aplicação de recursos públicos em educação como proporção do produto interno bruto.

Também são encontradas referências na Lei de Diretrizes e Bases da Educação Nacional (Lei 9.394/96), no art. 9, inciso I, (Brasil, 2017) que diz: “a União incumbir-se-á de: I. elaborar o Plano Nacional de Educação, em colaboração com os Estados, o Distrito Federal e os Municípios" e mais, no $\S 1^{\circ}$ do art. 87:

a União, no prazo de um ano a partir desta Lei, encaminhará ao Congresso Nacional o Plano Nacional de Educação, com diretrizes e metas para os dez anos seguintes, em sintonia com a Declaração Mundial sobre Educação para Todos.

Compete também aos Estados e Municípios, segundo a Lei $\mathrm{n}^{\mathrm{o}} 10.712$, de 09/01/2001, no art. $2^{\circ}$, fomentarem a construção dos seus respectivos planos: PEE - Plano Estadual de Educação e PME - Plano Municipal de Educação, criando as bases necessárias para sua formulação. A sociedade civil organizada entende que devem ser salvaguardadas as conquistas dos direitos sociais e resguardadas as políticas públicas educativas das descontinuidades, dada a rotatividade e os desmandos de diferentes governos.

De acordo o Instituto Nacional de Estudos e Pesquisa Educacionais (INEP), as 20 metas do PNE são acompanhadas de um delineamento de prazos específicos para cada uma dessas. Na dimensão cronológica envolve o estabelecimento de etapas bianuais para o acompanhamento do Plano como um todo, para as quais o INEP fica obrigado a publicar estudos mais aprofundados acerca da trajetória dos indicadores das metas, considerando os três níveis federativos e os grupos sociais prioritários para o Plano. O processo de monitoramento do Plano será contínuo e contará com um cronograma para o desenvolvimento e a publicação bienal dos estudos, que devem ser feitos pelo INEP (BRASIL, 2015, p. 16), como pode ser visualizado na Figura 1:

Figura 1 - Cronograma para a publicação de estudos sobre o PNE

pelo Inep

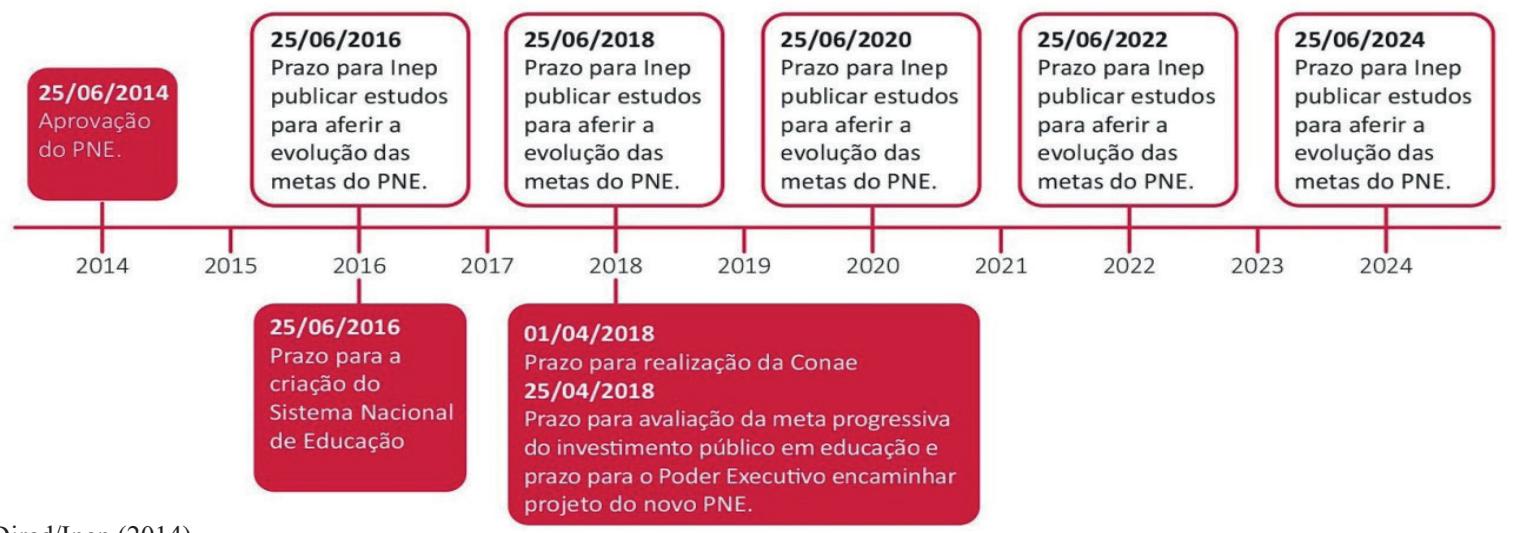

Fonte: Dired/Inep (2014).

No PNE, a meta que aborda a Educação Superior corresponde a Meta 12, que trata da expansão das matrículas nos cursos de graduação. Essa propõe:
Elevar a taxa bruta de matrícula na educação superior para $50 \%$ e a taxa líquida para $33 \%$ da população de 18 a 24 anos, assegurada à qualidade da oferta e expansão para, pelo menos, 40\% das novas matrículas, no segmento público (BRASIL, 2015). 
Essa meta remete a três aspectos: a) elevação da taxa bruta de matrícula na Educação Superior para $50 \%$ e a taxa líquida para 33\% da população de 18 a 24 anos; b) garantia da qualidade da oferta; c) expansão para, pelo menos, $40 \%$ das novas matrículas, no segmento público.

O alcance da meta 12 do PNE requererá grande esforço e planejamento do Estado brasileiro para alcançar os índices previstos até 2024. O desafio é ainda mais complexo quando se considera a desigualdade regional e estadual, o elitismo de algumas áreas e cursos e o grande contingente de jovens, que não consegue ter acesso ou permanecer na Educação Superior.

Dados recentes coletados pelo IBGE, conforme figura 2 abaixo, demonstram a proporção de pessoas de 25 anos ou mais de idade com Ensino Superior completo por unidade de Federação.

Figura 2 - Proporção de pessoas de 25 anos ou mais de idade com Ensino Superior completo por unidade de Federação - Brasil $-2017$.

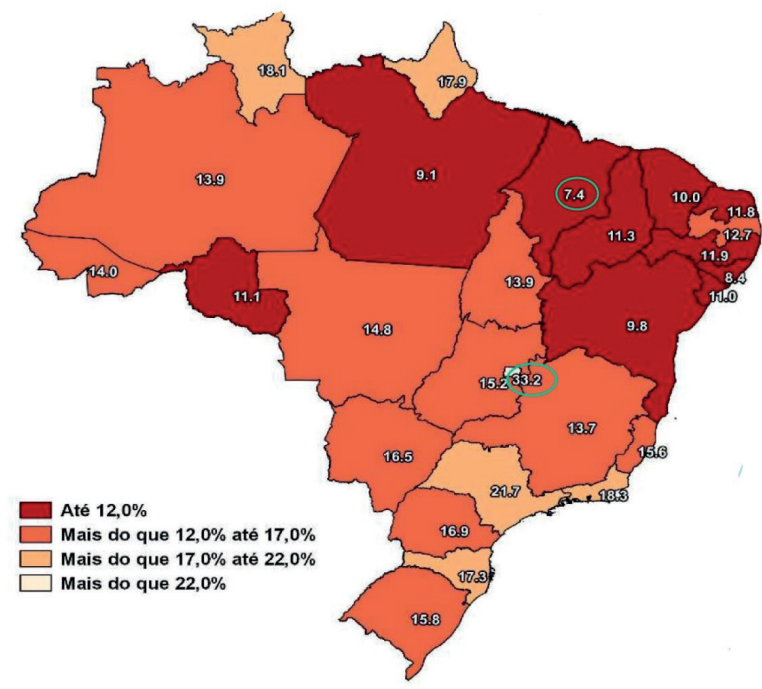

Fonte: IBGE (2017).

Diante desse mapa se observa que o Brasil é o país com alto nível de desigualdades entre suas unidades subnacionais (UF) no que tange à conclusão do Ensino Superior. Este indicador para o Distrito Federal - DF correspondeu em 2017, a 33,2\%, ou seja, $4,5 \%$ vezes maior do que o Maranhão $(7,4 \%)$.

Nos fins dos anos 1970 e durante a década de 1980, os debates sobre a democratização do Estado e a liberdade de expressão começam a tomar conta das associações representativas da sociedade civil, fortalecidos pelos movimentos sindicais, que elaboraram vários atos de contestação como as greves por melhores salários e condições de trabalho, ajudando no fervilhar da necessidade de repensar a organização social brasileira. Diante a pressão da sociedade e dos movimentos, foi promulgada em 1996, a Lei de Diretrizes e Bases da Educação Nacional (LDB), Lei no 9.394/96, que aponta os caminhos políticos na área de Educação.

Vale salientar que pela primeira vez foi implementada uma única lei de ensino, que contempla Educação Básica e Ensino Superior, uma vez que anteriormente havia leis específicas, a saber: Lei $n^{\circ} 4.024 / 61$, que continha os princípios filosóficos da Educação; Lei 5.692/71 que versava sobre a Educação de $1 .^{\circ}$ e $2 .^{\circ}$ graus; a Lei $5.540 / 68$, que organizava o Ensino Superior, e surgida em 1982, foi promulgada a Lei ${ }^{\circ} 7.044$, que alterou alguns dispositivos da Lei $\mathrm{n}^{0} 5.692$, referente à profissionalização do ensino de $2^{\circ}$ grau. A partir da atual legislação sobre a educação brasileira, foi incluso na LDB o ensino universitário, cabendo-lhe um capítulo exclusivo no Título V - Dos níveis e das modalidades de Educação e Ensino - Capítulo IV - da Educação Superior - obedecendo ao princípio da verticalidade da organização do ensino.

Ao mesmo tempo, com a promulgação, em 1996, da atual LDB foi conferido ao Estado brasileiro o controle e a gestão das políticas educacionais, ao mesmo tempo em que se flexibilizou a oferta da Educação Superior pela iniciativa privada.

Neste sentido, retomando a meta 12 do PNE, segundo Oliveira e Dourado (2018), no que diz respeito à garantia da qualidade do processo de expansão, aspecto também destacado na referida meta, o PNE traz apenas uma estratégia que aponta para a reestruturação dos procedimentos adotados na área de avaliação, regulação e supervisão. Neste sentido, segundo os autores, é fundamental garantir expansão com qualidade, tendo em vista que os indicadores existentes mostram baixo desempenho, especialmente em cursos de instituições privadas.

Além disso, ainda cabe frisar que para se efetivar o outro quesito, da meta 12 do PNE, deve-se aumentar em pelo menos $40 \%$ novas matrículas para o setor público, isso exigirá forte determinação do Governo Federal e definição de políticas e financiamento para sua concretização. Essa meta dificilmente será cumprida ao se considerar a forte tendência de expansão da Educação Superior privada, desde a segunda metade dos anos 1990, e que tem mantido a ampliação das matrículas dos cursos de graduação no setor privado no decorrer dos anos. O gráfico da Figura 3 apresenta esta predominância da rede privada de ensino entre as regiões do país.

Figura 3 - Taxa bruta de matrículas, por rede de ensino e grandes regiões - Brasil -2004/2013

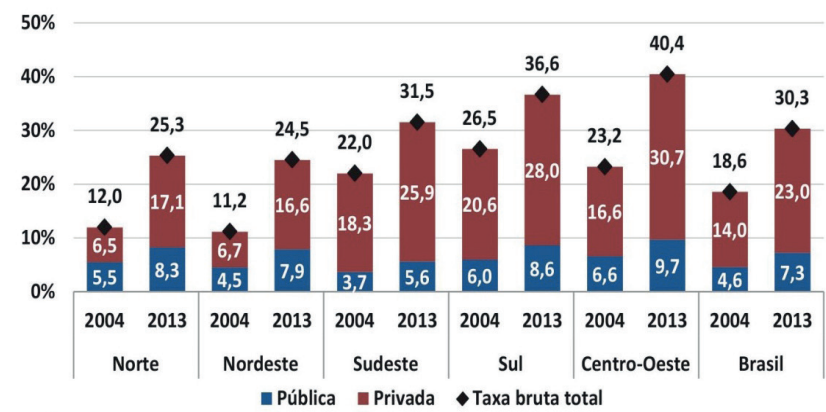

Fonte: Pnad/IBGE (2015).

De acordo dados do IBGE, em 2017, apresentados no gráfico da Figura 4, observa-se que a taxa de ingresso no Ensino Superior dos alunos oriundos da rede privada de Ensino Médio era mais do que o dobro daquela obtida pelos da rede 
pública. Esse diferencial entre redes de ensino permaneceu para as pessoas de 18 a 24 e de 25 a 44 anos de idade $(2,4$ vezes maior).

Figura 4 - Taxa de ingresso no Ensino Superior da população com Ensino Médio completo, por faixa de idade e cor ou raça, segundo rede do ensino médio concluído - Brasil - 2017.

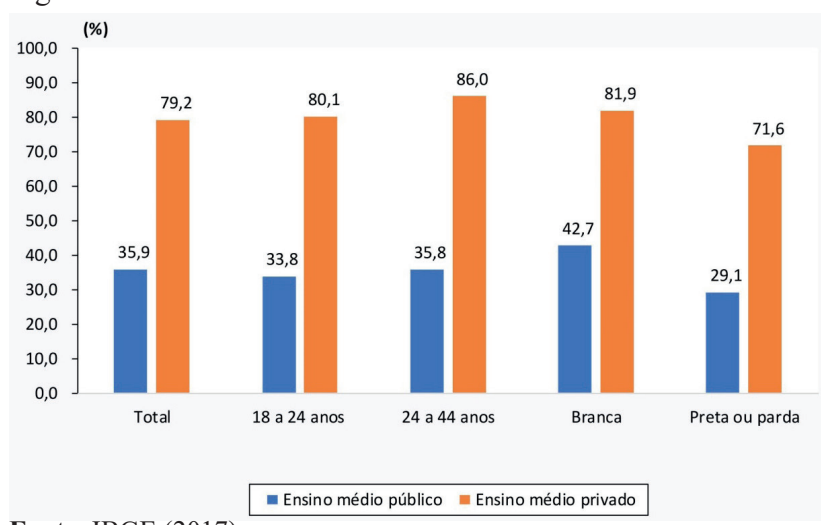

Fonte: IBGE (2017)

Ainda, segundo o gráfico da Figura 4, nota-se que os brancos apresentaram taxa de ingresso maior do que os negros e pardos, tanto na rede pública quanto na privada. Quando comparado às taxas de escolarização entre brancos e negros, conforme gráfico da Figura 5, nota-se a predominância das desigualdades raciais existentes no Brasil.

Figura 5 - Taxa bruta de matrículas, por rede de ensino - Brasil

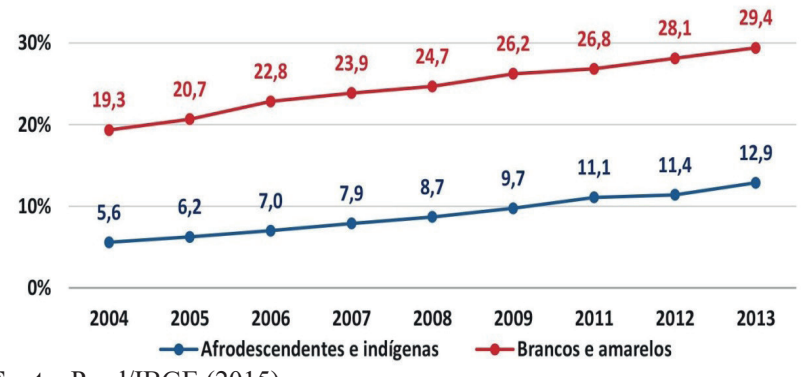

Fonte: Pnad/IBGE (2015).

No caso das desigualdades de raça/cor, a Taxa Líquida de Escolarização Ajustada (TLea) ${ }^{1}$ dos brancos e amarelos era 2,28 vezes maior do que a dos afrodescendentes e indígenas em 2013. O primeiro grupo já se encontra perto de atingir a meta nacional para o indicador, com $29,4 \%$ de acesso à Educação Superior entre a população de 18 a 24 anos, enquanto o segundo apresenta menos da metade desse valor, com apenas $12,9 \%$ de acesso. Todavia, pode-se observar uma redução em termos relativos entre ambos os grupos ao longo do último decênio, pois, em 2004, a Tlea dos brancos e amarelos era 3,45 vezes maior do que a dos afrodescendentes e indígenas. Apesar do crescimento observado na Tlea deste grupo entre 2004 e 2013, seu patamar no final do período era inferior ao dos brancos e amarelos em 2004.

Os (neo)liberais argumentam que, quando o sistema universaliza o ensino gratuito, independentemente da condição financeira dos alunos ou de suas famílias - em nome da igualdade - contribui para aumentar a desigualdade de oportunidades, uma vez que as famílias de baixa renda, de modo geral, só têm acesso à escola de baixa qualidade. As famílias de maior renda podem optar por escolas particulares de qualidade. Por isso, na visão liberal: se você não educa a massa, finge que está melhorando a vida dela, mas está aprofundando o fracasso que separa os brasileiros. Outra razão [...] é a eficiência [...], o que se desperdiça em termos de talento no Brasil, por que não se educa as crianças. É uma coisa trágica [...] uma cultura capitalista, baseada como é, na inovação, requer talento (MERQUIOR, 1983, p. 150).

No ideário liberal, os homens são iguais enquanto seres humanos, mas diferentes em suas habilidades e aspirações. Em nome da liberdade, é preciso que não se neguem as diferenças e as desigualdades. Segundo Freitas (2014), de acordo com a tese liberal, ir além do direito básico depende das "aptidões" e do "dom" das pessoas, ou seja, depende do esforço e mérito de cada um. Ainda destaca que os liberais não convivem com a igualdade de resultados, apenas com a igualdade de oportunidades:

mantêm-se intacto o funcionamento do processo de exclusão, transferindo-se a culpa, agora, para o próprio estudante quando aparecem as "justas diferenças" obtidas pelo mérito de ter aproveitado as oportunidades, para além do básico (obrigatório) esperado na porta das empresas. Ao trabalhador, o básico; às elites, a formação ampla (FREITAS, 2014, p. 1088).

Freitas (2014) ainda aborda sobre os vários sujeitos privados desses direitos, tanto individuais quanto coletivos, que em virtude da própria necessidade do capital se veem diante da contradição de qualificar um pouco mais a massa de trabalhadores da sociedade e, ao mesmo tempo, manter o controle ideológico da escola, diferenciando desempenhos, mas garantindo acesso ao conhecimento básico para a formação do trabalhador hoje esperado na porta das empresas. Assim sendo, tal contradição, move os reformadores a disputarem a agenda da educação, responsabilizando a escola pela falta de equidade no acesso ao conhecimento básico, assim como por não garantir o domínio de uma base nacional e comum a todos.

Estes reformadores, segundo Freitas (2014), são resistentes à oferta de investimentos na educação. Neste sentido, há de se acrescentar que o art. 68 da LDB (Brasil, 2017) explicita, de forma bastante clara, a origem dos recursos destinados à Educação, a saber: receita de impostos próprios da União,

1 Segundo o Inep, a taxa líquida de matrícula (TLM) é um indicador do acesso ao sistema educacional por aqueles que se encontram na idade prevista para cursá-lo. Já a taxa líquida de escolarização ajustada (Tlea) é um aperfeiçoamento do indicador "taxa líquida de matrículas", pois considera não apenas a população matriculada, mas também a população que já concluiu a educação superior e ainda se encontra na faixa etária recomendada para cursá-la. 
dos Estados, do Distrito Federal e dos Municípios; receita de transferências constitucionais e voluntárias; receita do salário-Educação e de outras contribuições sociais; receita de incentivos fiscais; e outros recursos previstos em lei. Cabe ainda destacar o art. 69 , ao prever que:

A União aplicará, anualmente, nunca menos de dezoito, e os Estados, o Distrito Federal e os Municípios, vinte e cinco por cento, ou o que consta nas respectivas Constituições ou Leis Orgânicas, da receita resultante de impostos, compreendidas as transferências constitucionais, na manutenção e desenvolvimento do ensino público (BRASIL, 2017, p.45).

No ano de 2016, a fim de atender ano novo regime fiscal, foi aprovada a emenda à Constituição, a PEC n ${ }^{\circ}$ 241/2016, que deu origem à EC 95 determinando o congelamento dos gastos direcionados à educação, por um período de 20 anos, a qual passou a vigorar em 2017. De acordo com o informativo técnico $n^{\circ}$ 6/2019-CONOF/CD (Brasil, 2019), o piso constitucional da educação em 2017 foi ainda equivalente a $18 \%$ da receita líquida de impostos.

Com base neste informativo, o levantamento foi feito levando em conta os orçamentos efetivamente realizados entre 2014 e 2018 e corrigidos pelo Índice Nacional de Preços ao Consumidor Amplo (IPCA). Observa-se a redução de investimento em despesas com educação. Segundo o informativo, a classificação da despesa por subfunção busca demonstrar a atuação governamental, distinguindo-se as ações finalísticas, que proporcionam bem ou serviço para atendimento direto a demandas da sociedade, das ações não finalísticas. Segundo o Gráfico 4, a seguir, as principais subfunções finalísticas do MEC - Ensino Superior, Educação Básica e Ensino Profissional - são as que sofrem maior redução, ainda que as despesas de pessoal ativo integrem essas subsunções (BRASIL, 2019).
Figura 6 - Ministério da Educação: Despesas por Grupo de Subfunções (R\$ bilhão, base 2019)

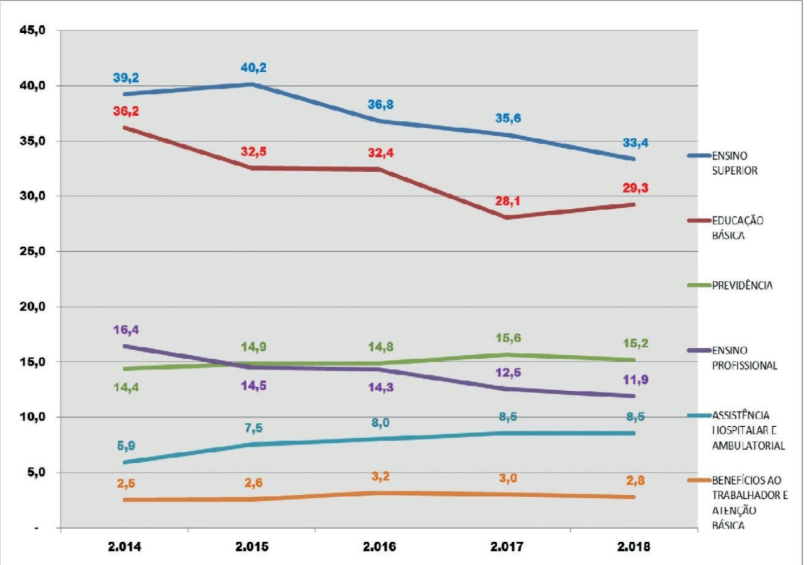

Fonte: Siafi (2019).

Diante dos dados apresentados no gráfico da Figura 6, observa-se que sofreu redução acumulada, no período 2014 2018, o valor gasto nos três níveis de ensino: básico, técnico e superior, sendo: Ensino Superior (-15,0\%), Educação Básica (-19,3\%), Ensino Profissional (-27,6\%), administração $(-3,2 \%)$, desenvolvimento científico e difusão $(-5,5 \%)$, demais (-6,5\%). Grupos de subfunções com acréscimo acumulado no período 2014-2018: previdência (5,7\%), assistência hospitalar e ambulatorial $(44,3 \%)$ e benefícios ao trabalhador e atenção básica $(11,9 \%)$.

Segundo Salati (2018), os investimentos do Ministério da Educação caíram 16\%, em termos reais, nos 12 meses encerrados em março de 2018, para R \$ 4.556 bilhões, ante igual período de 2017, ou seja, terceira queda seguida nessa base de comparação. A autora ainda frisa que os aportes para educação acumularam o maior valor em 2007, ao chegar em R\$ 13.665 bilhões e, ao analisar os cortes ocorridos para a educação, Salati (2018) destaca que os mesmos têm alcançado $66 \%$ em cinco anos.

Ao analisar dados do IBGE, quanto a amostra de domicílios continuada realizada no $2^{\circ}$ semestre de 2017 , há o gráfico 6 abaixo que apresenta a proporção de pessoal de 25 a 34 anos com Ensino Superior completo.

Figura 7 - Proporção de pessoas de 25 a 34 anos com Ensino Superior completo, segundo os países OCDE e Brasil - 2017.

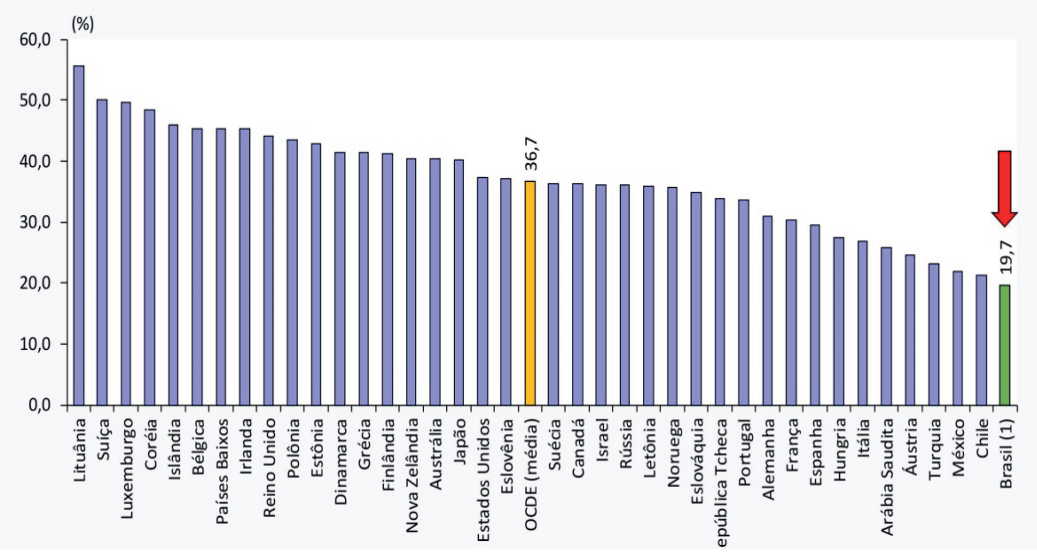

Fonte: Dados da pesquisa. 
De acordo o gráfico da Figura 7, a proporção de pessoas de 25 a 34 anos no Ensino Superior completo no Brasil é de pouco mais da metade do observado para a média dos países da OCDE, ou seja, a média corresponde a 36,7\%, enquanto o Brasil apresenta apenas $19,7 \%$ das pessoas com Ensino Superior completo, ficando, inclusive atrás de vizinhos latinoamericanos como o Chile e o México.

Segundo a Secretaria do Tesouro Nacional - STN (2018), o Brasil gasta atualmente, em educação pública, cerca de $6,0 \%$ do $\mathrm{PIB}$, valor superior à média da $\operatorname{OCDE}(5,5 \%)$ - que engloba as principais economias mundiais - e de pares como Argentina (5,3\%), Colômbia (4,7\%), Chile (4,8\%), México $(5,3 \%)$ e Estados Unidos (5,4\%). Cerca de $80 \%$ dos países, incluindo vários países desenvolvidos, gastam menos que o Brasil em educação relativamente ao PIB. No entanto, o Relatório do STN não leva em consideração que o Brasil ainda não possui um sistema de ensino universalizado, como os demais países citados pela OCDE, em especial, com países desenvolvidos.

Cabe destacar que se faz necessário trabalhar para melhorar a gestão dos recursos da educação. Além disso, comparar gastos do Brasil com países como os da OCDE, que historicamente investiram mais e têm bons indicadores há muito tempo, não é apropriado.

\section{Conclusão}

No reino do capital, a educação é uma mercadoria como algo lógico e natural. Daí a crise do sistema público de ensino, pressionado pelas demandas do capital e pelos esmagadores cortes de recursos dos orçamentos públicos. Uma sociedade que impede a emancipação só pode transformar os espaços educacionais em shopping centers funcionais à sua lógica do consumo e do lucro - mercantilização da educação.

Nesse cenário, alcançar o que está previsto para a Educação Superior no PNE exige uma mudança na condução das políticas educacionais para esse nível de ensino e um novo olhar sobre a questão. Um olhar que favoreça à consolidação de uma política de expansão e de interiorização das instituições superiores públicas com especial destaque para as Universidades e Institutos Federais. Além disso, cumprir a lei de cotas e consolidar políticas de assistência estudantil, que visem expandir e democratizar o acesso e permanência na Educação Superior pública no país. Também é imprescindível que sejam priorizados investimentos na educação, para que as políticas públicas se tornem eficazes.

Ao contrário do que é propagado pelo ideário do capital, o momento atual é de se investir mais em educação. Precisa ocorrer uma melhor gestão, mas também investir mais para ter o que foi definido como uma boa escola no Plano Nacional de Educação com biblioteca, quadra coberta e professor na sala de aula devidamente valorizado profissionalmente.

No entanto, as atuais manchetes informam o novo corte para Educação Básica (Folha de S. Paulo, 15/07/19)2 indicando que o atual governo, além de não investir, esvaziou ações voltadas para a Educação Básica, como programas de apoio a educação em tempo integral, construção de creches, alfabetização e ensino técnico. Segundo o jornal, os dados foram obtidos por meio da Lei de Acesso à Informação (LAI) e Sistema Integrado de Planejamento e Orçamento do Governo (Siop).

Vale ainda destacar que, com a naturalização do privado no público, a democratização da educação e da escola retrocedem, há um esvaziamento da participação, autonomia e transparência dos sistemas e as políticas de educação são impressas de cima para baixo, na contramão de um processo democrático e comprometido com as necessidades da população.

\section{Referências}

BRASIL. Câmara dos Deputados. Ministério da Educação: despesas primárias pagas 2014-2018 e impactos da EC 95/2016 (Teto de Gastos). Informativo Técnico no 6/2019-CONOF/CD. Brasília: Câmara dos Deputados/CONOF, 2019.

BRASIL. Constituição da República Federativa do Brasil. Brasília: Senado Federal, Coordenação de Edições Técnicas, 2016.

BRASIL. Instituto Nacional de Estudos e Pesquisas Educacionais Anísio Teixeira (INEP). Plano Nacional de Educação PNE 20142024: Linha de Base. Brasília, DF: Inep, 2015.

BRASIL. Ministério da Educação. Lei de Diretrizes e Bases da Educação Nacional. Brasília: Senado Federal, Coordenação de Edições Técnicas, 2017.

BRASIL. Ministério da Fazenda. Secretaria do Tesouro Nacional. Aspectos Fiscais da Educação no Brasil. Brasília: STN, 2018.

DOMINGUES, P. Um “templo de luz”!: a Frente Negra Brasileira (1931-1937) e a questão da educação. Rev. Bras. Educ., v.13, n.39, p.517-534, 2008.

FREITAS, L.C. Os reformadores empresariais da educação e a disputa pelo controle pedagógico na escola. Educ. Soc., v.35, n. 129, p.1085-1114, 2014.

LOMBARDI, J.C. Reflexões sobre educação e ensino na obra de Marx e Engels. Campinas: Universidade Estadual de Campinas, 2010.

MÉSZÁROS, I. A educação para além do capital. São Paulo: Boitempo, 2008.

MERQUIOR, J.G. O anarquismo liberal. Rio de Janeiro: Nova Fronteira, 1983.

OLIVEIRA, J.F.; DOURADO, L.F. Meta 12 - Educação Superior. In: OLIVEIRA, J.F.; GOUVEIA, A.B.; ARAÚJO, H. Caderno de avaliação das metas do Plano Nacional de Educação: PNE 20142024. Brasília: ANPAE, 2018. p.46-47

PERONI, V.; CAETANO, M.R.; LIMA, P. Reformas educacionais de hoje: as implicações para a democracia. Rev. Retratos Escola, v.11, n.21, p.415-432, 2017.

ROUSSEAU, J.J. Do contrato social: ou princípios do direito político. São Paulo: Abril Cultural, 1983.

SALATI, P. Em 5 anos, governo federal cortou $66 \%$ dos 
investimentos em educação. São Paulo: Diário, Comércio, Industria e Serviços (DCI), 2018.

VIDA, S. O racismo institucional e as ações afirmativas enquanto dever do Estado. In: FUNDAÇÃO CULTURAL PALMARES. $O$ negro no mercado de trabalho. Brasília: Ministério do Trabalho e Emprego, 2005. 